\title{
Moderating Role of Social Factors on the Effect of Integrated Marketing Communication on Performance of Fast Food Restaurants in Nairobi Central Business District, Kenya
}

\author{
Musyimi Peris Mueni", Wambui E Ng'ang'a\#, Julie Makomere" and Robert Onyango^ \\ \#University of Eldoret, Kenya \\ Masinde Muliro University of Science and Technology, Kenya
}

Received 15 Aug 2018, Accepted 17 Oct 2018, Available online 20 Oct 2018, Vol.6 (Sept/Oct 2018 issue)

\begin{abstract}
Universally Integrated Marketing Communication (IMC) plays a pivotal role in providing adequate intrinsic information which impacts on overall performance of fast food restaurants. In this regard the study was designed to assess the moderating role of social factors on the effect of integrated marketing communications on the performance of fast food restaurants in Nairobi central business district. The study was guided by the following specific objectives; to examine the role of public relations, social media networks, sales promotion and advertising on the performance of fast food restaurants in Nairobi CBD. To determine the moderating role of social factors on the effect of intergraded marketing and communication on the performance of fast food restaurants in Nairobi CBD. The study adopted an explanatory research design. The target population was 144 key informants which included 48 managers and 96 heads of departments sampled from all the 48 fast food restaurants in Nairobi CBD. In this study census sampling technique was adopted to arrive at the sample size which is 144 key informants. Data was collected by use of structured and unstructured questionnaires from the key informants. Collected data analyzed by use of both inferential and descriptive statistics using SPSS version 20. Result of multiple regressions revealed that social factors moderates the relationship between integrated marketing communication and the performance of fast food restaurants with $F=60.279$ at $P=.000$. Jointly the four constructs namely public relations, social media networks, sales promotion and advertisement with a moderator jointly explained $73.6 \%\left(R^{2}=0.736\right)$ variation in performance of fast food restaurants. The 6 value for public relations (.233), social media networks (.232), sales promotion (.340), advertising (.295), were positive. Correlations between public relations, social media networks, sales promotion, and advertising $r=.677^{* *} r=.579^{* *}, r=.693^{* *}$ andr $=.411^{* *}$ respectively. They were also positively and significantly related to performance of fast food restaurants where $P<0.01$. All these together led to the rejection of the null hypothesis. This implies that the management of fast food restaurants should pay high premiums in strategically formulating and implementing IMCs which can effectively galvanize high performance of fast food restaurants.
\end{abstract}

Keywords: Social Factors, Integrated Marketing Communication, Performance

\section{Background}

In the contemporary era it is almost universally accepted idea that the main purpose of existence of restaurants is satisfying the consumer, which engenders their maximal performance. In this regard Integrated Marketing Communication (IMC) plays a pivotal role to fast food restaurants by providing adequate intrinsic, employment status, educational level and cultural differences (Dowler, 2001). It is only through performance that fast food restaurants that they are able to grow and progress (Nganga', Lagat \& Kiet, 2016)

*Corresponding author's ORCID ID: 0000-0003-3323-3313

DOI: https://doi.org/10.14741/ijmcr/v.6.5.19
Hotels use appropriate strategies to meet and exceed the expectations of their customers which in turn engenders high performance (Kangogo, Musiega., \& Manyasi, 2013). The most effective ways by which consumers' needs could be satisfied is one of the main objectives of IMC (Camelia, 2012). Fast food restaurants just like hotels must view customer relationship as an asset, consider customer retention as a priority and be committed to meeting customers' needs and expectations (Wambui et al, 2016).

IMC is an interactive and systemic process of crossfunctional planning and optimization of messages to stakeholders with the aim of communicating with coherence and transparency to achieve synergies and encourage profitable relationships in the short, medium 
and long-term value (Porcu, Salvardor \& Kitchen, 2012). IMC represents an alternative approach that can replace traditional marketing approaches focused on transactions as it is consumer-oriented and focused on a relationship marketing approach (Christensen et al, 2008). Marketing has evolved from a logic focused on transactions and products to being focused upon the development of longterm relationships and the underlying improvement of resources and competencies in order to create and sustain customer value (Porcu et al., 2012).

Consumers need to be persuaded through effective communication to the positive attributes that functional foods offer or represent so that they can link the health effects and superior quality attributes to the product (Fill \& Jamieson, 2006). A person might be able to acknowledge the health or environmental benefits of consuming a food without which they will be less likely to consume it (Wansink et al., 2005).According to Fill and Jamieson, (2006) educating consumers through effective marketing communication is crucial in boosting sales and consequently performance of fast food restaurants. This position is corroborated by many authors who highlight the positive impact of marketing communications on performance of fast food restaurants (Schultz et al., 1997; Low, 2000; Ewing, 2009 ).

In the contrary Nana et al.(2011) notes that despite the huge investments and the concerted efforts in IMC, many organizations are not successful because the impact on a customer's behavior is uncertain. This poses challenge to most trading firms, fast food restaurants being no exception, on how to measure and evaluate the impact of their IMC efforts on their business performance as a whole. However it remains quintessential for fast food restaurants to embrace IMC strategies for purposes of projecting an image of uniqueness for competitive advantage.

In a global market characterized by high dynamism and fierce competition customers need understand the benefits that can be obtained by consumption or use of products or services of fast food restaurants to increase their performance (Clow, 2010). Ashton, et al. (2010) opines that in past three decades the fast food restaurant industry has experienced one of the highest business failure rates an index of poor performance. A Company's marketing communications effectiveness generates favorable performance in Slovenian companies (Damjana \& Bruno, 2012). Eastern Bloc countries are in direct competition with Ireland as a tourism destination calling for the adoption of IMC as a marketing strategy as a panacea (Corr, 2007). Kentucky Fried Chicken (KFC), Nando's, and Steers in the fast food industry in South Africa is experience performance challenges hence intensifying their marketing strategies as a defensive way to counter the impact imposed by competition (Mornay, 2009). According to Kenya Food Market Report (2017) The restaurant business in Kenya has been growing rapidly over the last couple of years evidenced by the expansion of major food chains in Kenya such as Java and the entrance of new international brands in the country.
However the hotel industry faces a lot of marketing challenges compromising on their performance (Zhao \&Jing, 2009). Nonetheless, lack of empirical evidence about the role of IMC on the outcomes obtained by the organization, it is difficult to specify accurately the effects of IMC on performance of fast food restaurants just like other organizations (Porcu et al., 2012). However, from an operational perspective, it can be deduced that IMC is likely to produce benefits in the coordination of marketing communication activities. Despite this there is a general agreement that much more research in this area is needed (Damjana \& Bruno, 2012). Besides there are limited studies done in the Kenyan context regarding the moderating role of social factors on the relationship between integrated marketing communication and performance of fast food restaurants. This altogether has informed the design of the current study to fill in the existing gap in literature.

\section{Statement of the Research Problem}

Determining and satisfying the needs of customers through products that have value and accessibility and whose features are clearly communicated is the general purpose of any business (Burnett, 2008). It is therefore fundamental for fast food restaurants to embrace integrated marketing communication in order to inform customers of their products for maximal performance. Customers are a critical component of performance of the fast food restaurants (Flanagan, 2005). Therefore enhancing customer satisfaction can engender high performance of the fast food restaurants. This can be achieved through communication of a good and clear concept which conveys a message and an image of the fast food restaurant to the customers. The sector accounts for a significant growth of $4.1 \%$ which has lead to rigid marketing to attract and maintain a commanding market share of Nairobis $3.8 \mathrm{M}$ residents to spur the performance of the fast food restaurants (Afamah, 2017). This coupled by the use of traditional marketing approach by fast food restaurants to attract customers who are diverse in perception and expectation of what good service constitutes poses a marketing challenge to the hotel industry (Uzel, 2012). The downside of traditional marketing is the high cost and it is a one-way communication (Cave, 2016).

IMC represents an alternative approach that can replace traditional marketing approaches (Aka et al, 2016).IMC helps hotels integrate the different needs of customers due to the two way nature of communication thus increasing their performance (Cave, 2016). Bantock (2017) in his study on IMC: improving the performance of McDonalds found out that IMC increased performance of McDonalds. Davydova (2016) in his study on IMC in restaurant chains found out that the success of the company depends on evaluation of the IMC strategy and specific rules for an efficiency of its' components. Cheruiyot, (2014) in her study on IMC and performance of 
Kenya Post and Savings Bank found that IMC enhance the company's performance.

Nonetheless, there is a general agreement that much more research in this area is needed (Damjana \& Bruno, 2012). In addition there are limited studies done in the Kenyan context regarding the moderating role of social factors on the effect of integrated marketing communication on performance of fast food restaurants. This altogether has informed the design of the current study to fill in the existing gap in literature by assessing the moderating role social factors on the relationship between IMC and performance of fast food restaurant in Nairobi CBD.

\section{Objective}

To determine the moderating role of social factors on the effect of integrated marketing and communication on the performance of fast food restaurants in Nairobi CBD

\section{Hypothesis}

$\mathbf{H o}_{1}$ : There is no significant moderating role of Social factors on the effect of integrated marketing communication on performance of fast food restaurants in Nairobi CBD.

\section{Literature Review}

\section{Concept of Performance}

Performance is a measure of the results achieved. Performance efficiency is the ratio between effort extended and results achieved. The difference between current performance and the theoretical performance limit is the performance improvement zone (Law, 2013). Performance assumes an actor of some kind but the actor could be an individual person or a group of people acting in concert. The performance platform is the infrastructure or devices used in the performance act (Ismael et al., 2010). There are two main ways to improve performance: improving the measured attribute by using the performance platform more effectively, or by improving the measured attribute by modifying the performance platform which in turn allows a given level of use to be more effective in producing the desired output (Short \& Palmer, 2003).

Performance relates to how successfully an organized group of people with a particular purpose perform a function (Louise, 2012). Performance can be defined as the extent to which organizations meet its objectives. Performance is determined in light of the organization's goals and the strategies put in place to achieve those goals. Organizational performance refers to how well an organization is doing to reach its vision, mission, and goals (Short \& Palmer, 2003). The primary goals of IMCs are to increase effectiveness and efficiency which improves the ability of the organization to deliver goods and or services (Osisioma et al, 2016). At the organizational level, performance improvement usually involves softer forms of measurement such as Guest satisfaction and Customer turnover surveys which are used to obtain qualitative information about performance from the view point of customers.

The current study measures organization performance by use of Guest satisfaction and customer turnover. Customer satisfaction is another key performance indicator for restaurants. Restaurant companies usually like to measure key elements of their restaurant, such as food quality, hospitality, speed of service and cleanliness. Some restaurants use mystery shoppers to visit their units at unannounced times (Suttle, 2017). Most restaurants keep track of their advertising expenditures and return on investment. For example, many restaurants advertise in coupon magazines that are distributed to residences in their area. The restaurant will usually keep track of the number of customers who use the coupons (Wright B. 2016).

\section{Integrated Marketing Communications (IMC)}

Integrated Marketing Communications is a strategy in which different communication tools like advertising, public relations, social media, sales promotion, direct marketing and personal selling work together to maximize the communication impact on target consumers (Rashid et al., 2013). Integrated marketing entails the co-ordination of all the marketing activities, in order to maximize all the joint effects. An IMC (as part of integrated marketing) would thus involve choosing marketing communication options that reinforce and complement one another (Kotler \& Keller., 2006).

Each strategy has its own importance which can be accessed from the results and impact of that strategy. IMC is proposed as a key competitive advantage in many organizations (Weilbacher, 2001; Smith, 2002) because sales and profit can be increased while saving the time, money and stress by applying IMC (Weilbacher, 2001; Smith, 2002).It makes easy availability and access of goods and services and makes message more efficient and reduces product related risks in the mind of consumers (Rashid et al., 2013). Therefore IMC remains critical in ensuring that all aspects of a brand's marketing communication is delivered in a consistent message towards that end.

According to Tsikirayi et al. (2012) budgetary restrictions and poor quality product as barrier in planning and implementing the IMC. The attendant consequences of budgetary restriction are poor promotion which undermines the sale of good quality product, while poor quality product negates the impact of good promotion due to boycott of product by the users. Vantamay,(2011) indicated the five factors to measure the effectiveness of IMC program; these factors are Customer responses, Market performance, Brand exposures, Communication effect and Channel support. This study will assess how the tools used in integrated 
marketing communication affects the performance of fast food restaurants in Kenya.

\section{Fast Food Restaurants in Kenya}

Fast food restaurants quick service food outlets specializing in serving meals such as chicken, chips, soft drinks and hamburgers. Many businesses are shifting their focus to meet the growing demands of consumers for example most supermarkets now include a deli, bakery, and a prepared-foods section as well as offer fastfood service (Linda, 2013). Media has played its own important role in creating socials perception on changing trends on health and lifestyle in the food industry (Abhijeet, 2016 ). It can therefore be argued that this has shifted eminence to healthy foods, adopting low calorie foods and aspersions to junk food.

The Kenyan restaurant business scene has witnessed a radical transformation not only due to new foreign entrants come in, but also a revolution in the strategies that the existing players employ (Kaniu, 2007). In this regard most of the restaurants have engaged in aggressive promotional campaigns while others have decided to venture on specific niche of the market. In the restaurants business, competition has been intense with foreign firms from countries such as South Africa setting shops locally. Nairobi has specifically seen the establishment of a number of foreign owned restaurants. The up market places and the suburbs of the City have become host for Italian, Chinese, Ethiopian, Indian and French delicacies specialists besides the local restaurants. Majority of these restaurants are situated in Lavington, Upper Hill, Kilimani, Parklands and Westland's areas of the City. In this regard the current study seeks to find out whether the IMC has got a role in the growth of these restaurants in the Kenyan market which is culturally diverse.

\section{Moderating role of Social Factors on the effect of IMC on Performance of Fast Food Restaurants}

The socio-cultural aspect of a society improves the efficiency of fast food restaurants, with increased civilization people prefer to enjoy life and taking meal outside the home (Aazir \& Qazi, 2012). The food intake of the people of any country is related to a number of factors like income of consumers, employment status, educational level and cultural differences (Dowler, 2001). Due to global change the life styles of people change gradually, they spend more money on fast food rather than spending on higher education, computers, books, magazines, newspapers, videos and recorded music (Schlosser, 1998).

Few studies have examined the effects of neighborhood access to fast food outlets on individual health outcomes. The studies that have taken place have all been in the U.S, and there is scant evidence for an association between access to fast food retailing and individual health outcomes (Burdette \& Whitaker, 2004). A positive correlation was built between per capital income of customers and visit of customers to different type of restaurants. Customers with higher incomes go to restaurants more frequently in comparison with customers with lower incomes. Fast food business has pessimistic effect on social practices of the general public, as the gain in the mass (weight) is found to be directly proportional to the fast food especially in women (Jeffery \&French; 1998). The customers pay out at fast food outlets shows the better life style of people according to economic condition (Deane; 1987). According to Deane, these factors affect the advancement of fast food industry and with a better management to these circumstances managers can raise profit and remain upto-date with time.

The restaurants have adopted healthier menus. They included more and more low calorie options. However, it is not just the health trends; other trends have also affected the industry. Brands are focusing on attracting and retaining customers. They have made their menus and services customer friendly. Increased staff hospitality and better delivery options have again brought customers flocking to fast food joints. The fast food brands like McDonalds, KFC, Dominos, Subway and Wendy's have focused on reputation, better service and healthier food (Ansari \& Joloudar, 2011).

Reputation has become important for two reasons. First, it is the competition between the brands. From McDonalds to Subway, there are hundreds of global and local brands competing for market share (Abhijeet, 2016). Next, it is an era of social shares. Any negative news can spread like wild fire and can immediately affect your public image. Losing reputation in the markets means losing customers. However, the brands remain more than ready to respond to such disruptive attacks. They keep well managed social media accounts to engage their fans and followers and to respond to concerns in real time.

Moreover, the attack on junk food led to people adopting low calorie foods. Such changing social trends impact the sales of the entire industry. The industry was held liable for the increasing childhood obesity (Ashton, et al., 2010). As a result, it had to adopt measures like showing the nutritional content on the label and reduce calories in the items. Cultural factors might also play an important role since some cultures do not encourage the consumption of fast food. Still, most cultures have adopted it with changes to suit the local preference (Abhijeet, 2016). Social communications can effectively boost users' behaviors to be in accordance with an online social community, thus facilitate their acceptance and responses toward social media advertising, with users' group intention as an intervening factor (Fue et al., 2017). In fine Social capital, which refers to the wealth of one's "connections", are fundamental to subsistence markets and in consequence performance of an enterprise (Andrés \& Blocker, 2015). 


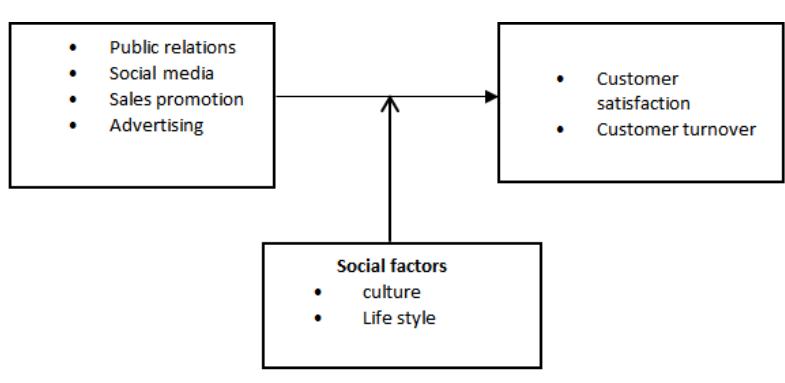

Adopted from (Damijan et al., 2007;Damjana \& Bruno, 2012)and modified by researcher 2018

\section{Research Methodology}

\section{Research Design}

This study adopted a explanatory research design. Explanatory Research is conducted in order to help us find the problem that was not studied before in-depth (Yousaf, 2018). It is actually a type of research design which focuses on explaining the aspects of your study in a detailed manner. The main aim of explanatory research is to identify any causal links between the factors or variables that pertain to the research problem.

\section{Target Population}

According to Mugenda and Mugenda (2012) a population is a complete set of cases, objects or individuals with some common characteristics that are observable. The target population will be 144 employees from the large fast food restaurants operating in the Nairobi County Council Licensing Data, 2016 (NCBD). Amongst the targeted population, 48 were be general managers while service manages and head chefs will be 96 key informants which will be purposively picked from the fast food restaurants.

\section{Sampling Technique}

A sample size refers to the number of people in the respondent group determined by the scope of the research (Collis \& Hussey, 2009). An ideal sample should neither be excessively large nor too small Kothari, (Collis \& Hussey, Business research: A practical guide for undergraduate and postgraduate students, 2014). Sample designs may be based on two factors; the representation principle and the element selection technique. In this study census sampling technique adopted to arrive at the sample size which is 144 key informants. Mugenda and Mugenda, (2012) explains that census is an enumeration of all items in a population which must be consistently defined for the purpose of study. A census survey was adopted as it collects complete information from all participants in the population. Census was adopted because it enhances the acquisition of detailed information about small sub-groups within the population.

\section{Data Collection Instrument}

A structured and pre-tested questionnaire based on the specific objectives was used to gather quantitatively data. A five point attitudinal scaling were used to measure levels of attitude or extent to which they agree or disagree with a particular question or statement. Questions involving both open and closed ended questions. The items adopted a 5 point Likert Scale (1Strongly disagree, 2-Disagree, 3-Undecided, 4-Agree and 5-Strongly agree).

\section{Data analysis and Presentation}

Data was analyzed using descriptive and inferential statistical techniques where under inferential statistics multiple regressions was used to determine the effect of a set of independent variable (IMC ) on dependent variable(performance of restaurants), coefficient of correlation, An ANOVA test was used to figure out whether there is need to reject the null hypothesis or accept the alternate hypothesis. Data was analyzed using the Statistical Package for Social Sciences (SPSS) Version 24.0 package.

The regression model is as follows:

$y=60+b_{1} X_{1} * Z+b_{2} X_{2} * Z+B_{3} X_{3} * Z+b_{4} X_{4} * Z+\varepsilon$

Where $Y$ is performance of restaurants, dependent variable; $x$ is IMC, 6 is the standardized regression coefficient.

$\beta_{1} \ldots \beta_{4}=$ the slope representing degree of change in independent variable by one unit variable.

$\mathrm{X}_{1}=$ Public relations,

$\mathrm{X}_{2}=$ Social media networks

$\mathrm{X}_{3}=$ Sales promotion

$\mathrm{X}_{4=}$ Advertising

$\mathbf{Z}=$ Social factors as the moderating variable

$\boldsymbol{\varepsilon}=$ Error term

$B 0=\mathrm{y}$ intercept

\section{Data Analysis, Results Findings and Discussion}

\section{Response Rate}

Out of a target population of 144 respondents as sample size was adopted. Subsequently. A total of 126 questionnaires were returned from which, 12 questionnaires were discarded for either lack of response, being improperly filled, or being incomplete. The researcher ended up with 114 correctly filled questionnaires, which represented a response rate of $79 \%$. This response rate was deemed adequate for external validity. According to Babbie (2002) any response of $50 \%$ and above is adequate for analysis thus $91 \%$ is even better. 


\section{Correlation}

Pearson's correlation coefficients were used to test linearity assumption. The purpose of using correlation was to identify IMCs that provide best predictions for conducting regression analysis. The inter-correlations among the variables are shown in Table 4.1. From the results, it can be seen that correlations among the IMCs were significant. Correlations between public relations, social media, sales promotion, advertising and social factors, where $r=.677^{* *}, r=.579^{* *}, r=.693^{* *}, r=.411^{* *}$ $r=.603^{* *}$ respectively were also positively and significantly related to performance of fast food restaurants where $\mathrm{P}<0.01$.

This implies that all the IMCs and social factors under study jointly have a positive and significant impact on performance of fast food restaurants in Nairobi CBD as such it behooves the management of the fast food restaurants to pay high premiums on these social factors to secure high performance of fast food restaurants.

Table 4.1: Correlation

\begin{tabular}{|c|c|c|c|c|c|c|}
\hline & Public relations & Social Media & Sales Promotion & Advertising & Social factors & Performance \\
\hline Public relations & 1 & & & & & \\
\hline Social Media & $.551^{* *}$ & 1 & & & & \\
\hline Sales Promotion & $.599^{* *}$ & $.382^{* *}$ & 1 & & & \\
\hline Advertising & .159 & .092 & .181 & 1 & & \\
\hline Social factors & $.510^{* *}$ & $.469^{* *}$ & $.548^{* *}$ & $.199^{* *}$ & 1 & \\
\hline Performance & $.677^{* *}$ & $.579^{* *}$ & $.693^{* *}$ & $.411^{* *}$ & $.603^{* *}$ & 1 \\
\hline
\end{tabular}

Table 4.2: Goodness of fit model summary

\begin{tabular}{ccccccc}
\hline Model & $R$ & R Square & $\begin{array}{c}\text { Adjusted R } \\
\text { Square }\end{array}$ & $\begin{array}{c}\text { Std. Error of the } \\
\text { Estimate }\end{array}$ & R Square Change & Durbin-Watson \\
\hline 1 (With moderator) & $.858^{\mathrm{b}}$ & .736 & .724 & .235 & .010 & 1.453 \\
\hline
\end{tabular}

a. Predictors: (Constant), Public relations, Social media, Sales promotion, Advertising and Social factors c. Dependent Variable: Performance of fast food restaurants

Table 4.3 ANOVA

\begin{tabular}{lccccc}
\hline & Model & Sum of Squares & $\mathrm{df}$ & Mean Square & $\mathrm{F}$ \\
\hline \multirow{3}{*}{1 (Moderator) } & Regression & 16.674 & 5 & 3.335 & 60.279 \\
& Residual & 5.975 & 108 & .055 & \\
& Total & 22.649 & 113 & & \\
\hline
\end{tabular}

a. Dependent Variable: Performance of fast food restaurants

b. Predictors: (Constant), Public relations, Social media, Sales promotion, Advertising and Social factors

Moderating role of social factors on the effect of integrated marketing communication on performance of fast food restaurants

From the model summary Table 4.2 of multiple regression model, the results showed that all the four predictors (Public relations, Social media, Sales promotion and Advertising ) with a moderator the variables jointly explained $73.6 \%\left(R^{2}=0.736\right)$ variation in performance of fast food restaurants. Which implies that when fast food restaurants embrace integrated marketing communication and proactively formulate policies in support of integrated marketing communication, then performance of fast food restaurants is likely to improve? Table 4.3 reveals that the F-value of 60.279 and a $p$-value of 0.00 significant at $5 \%$ level of confidence indicate that the overall regression model is significant, hence, the joint contribution of the independent variables was significant in predicting performance of fast food restaurants is likely to improve. In this regard, we reject the null hypothesis stating that there is no significant moderating role of social factors on the relationship between the predictors of integrated marketing communication and Performance of fast food restaurants. Instead, the alternative hypothesis will hold true; stating that there is a significant moderating role of social factors in the relationship between predictors of integrated marketing communication and performance of fast food restaurants

Regression coefficients of fast food restaurants as explained by IMC

Results of the regression coefficients presented in Table 4.4 show the estimates of Beta values and give an individual contribution of each predictor to the model. The Beta value tells us about the relationship between performance of fast food restaurants with each predictor. The positive Beta values indicate the positive relationship between the predictors and the outcome. With social 
factors as the moderator the Beta values for Public relations (.233), Social media (.340), Sales promotion (.295) and Advertising (.131) were also positive. The positive $B$ values indicate the direction of relationship between predictors and outcome. From the results in Table 4.48 the model can then be specified as:

$Y=.233 X_{1} * Z+.232 X_{2} * Z+.340 X_{3} * Z+.295 X_{4} * Z+\varepsilon$

Where:

$\mathrm{X}_{1}=$ Public relations

$\mathrm{X}_{2}=$ Social media

$\mathrm{X}_{3}=$ sales promotion

\section{$\mathrm{X}_{4}=$ Advertising}

T-test was then used to identify whether the predictors were making a significant contribution to the model. When the t-test associated with Beta value is significant then the predictor is making a significant contribution to the model. The results show that with a moderator Public relations $(t=3.553, P<.05)$, Social media $(t=3.783, P<.05)$, Sales promotion ( $t=5.147, P<.05)$ and Advertising $(t$ $=5.814, \mathrm{P}<.05)$. These findings indicate that all the predictors of integrated marketing communication jointly significantly affect on performance of fast food restaurants with or without a moderator.

Table 4.4 Regression coefficients of social factors and predictors of integrated marketing communication

\begin{tabular}{|c|c|c|c|c|c|c|c|c|}
\hline \multirow{2}{*}{\multicolumn{2}{|c|}{ Model }} & \multicolumn{2}{|c|}{ Unstandardized Coefficients } & \multirow{2}{*}{$\begin{array}{c}\begin{array}{c}\text { Standardized } \\
\text { Coefficients }\end{array} \\
\text { Beta }\end{array}$} & \multirow[t]{2}{*}{$\mathrm{T}$} & \multirow[t]{2}{*}{ Sig. } & \multicolumn{2}{|c|}{ Collinearity Statistics } \\
\hline & & $\mathrm{B}$ & Std. Error & & & & Tolerance & VIF \\
\hline \multirow{6}{*}{1} & (Constant) & .477 & .222 & & 2.149 & .034 & & \\
\hline & Public relations & .173 & .051 & .233 & 3.553 & .001 & .508 & 1.969 \\
\hline & Social Media & .186 & .049 & .232 & 3.783 & .000 & .648 & 1.544 \\
\hline & Sales Promotion & .205 & .040 & .340 & 5.147 & .000 & .559 & 1.788 \\
\hline & Advertising & .189 & .032 & .295 & 5.814 & .045 & .951 & 1.052 \\
\hline & Social Factors & .112 & .055 & .131 & 2.045 & .043 & .599 & 1.668 \\
\hline
\end{tabular}

Dependent Variable: Performance of fast food restaurants

\section{Hypotheses Testing}

$\mathbf{H o}_{1:}$ There is no significant moderating role of Social factors on the effect of integrated marketing communication on performance of fast food restaurants in Nairobi CBD. This hypothesis postulated lack of a significant effect of moderating role of Social factors on the effect of integrated marketing communication on performance of fast food restaurants in Nairobi CBD. From multiple regression results the value of $\mathrm{F}=60.279, \mathrm{P}<0.05$ in table 4.25 . These results are providing sufficient ground for rejection of null hypotheses and accepting alternate hypotheses. In fine, it has been found to be true that Social factors significantly moderates the effect of integrated marketing communication on performance of fast food restaurants in Nairobi CBD. Social factors can affect consumer behaviors which is fundamental to subsistence markets and in consequence performance of an enterprise (Andrés \& Blocker, 2015; Fue et al., 2017).

\section{Discussion and Conclusion}

In the context of restaurants, Chow et al.(2007) have found that social factors such as gender, age and income level, culture and lifestyle of consumers affected their repeat purchase intention. Social factors influence Customers' dining motivations which moderate the relationship between restaurant experiences and perceptions of brand image (Jin, Lee, \& Huffman, 2012). From the findings of this study there is a significant moderating role of social factors on the effect of integrated marketing and communication on the performance of fast food restaurants in Nairobi CBD with an F-value of 60.279 and a p-value of 0.00 . This is underpinned by the findings of Andrés \& Blocker, (2015);Fue et al.(2017) who found apositive and significant moderating role of social factors on the relationship between IMC and organization performance. This implies that mangers should develop integrated marketing communication strategies in cognizance of social factors in order to develop a positive brand image and behavioral consequences amongst their clientele base.

These findings suggests that in the light of social factors, IMCs as a concept, when embraced by the fast food restaurants will contribute extensively to improving their. The synergistic effect of the social factors and IMCs understudy cannot gainsaid in achieving high performance of fast food restaurants. This implies that the management of fast food restaurants should pay high premiums in formulating and implementing IMCs strategies in tune with social factors to effectively galvanize customer motivation and performance of their restaurants. The IMC should be bundled through mutually consistent policies to enhance their synergy in achieving high performance of the restaurants. In fine strategic orientation of these IMCs and social factors remains the cornerstone for enhancing performance of fast food restaurants in Nairobi CBD.

\section{References}

[1]. Aazir, H. M., \& Qazi, R. (2012). Impact of External Environment on the Performance of the Fast Food Industry. 
International Journal of Management, Economics and Social Sciences , 1(1), $19-25$.

[2]. Afamah, C. (2017). Supply chain integration and supply chain performance of fast fod chain restaurants in Nairobi County Kenya. University of Nairobi Unpublished thesis .

[3]. Allison, P. (2015). Heteroskedasticity. Retrieved 0711 , 2018, from www3.nd.edu/ rwilliam/

[4]. Andrés, B., \& Blocker, C. (2015). The Contextual Value of Social Capital for Subsistence Entrepreneur Mobility. Journal of Public Policy \& Marketing: , 34( 2) 272-286.

[5]. Ansari, M., \& Joloudar, S. (2011). An Investigation of TV Advertisement Effects on Customers' Purchasing and Their Satisfaction. International Journal of Marketing Studies, 3(4), 175 - 181.

[6]. Burdette, H., \& Whitaker, R. (2004). Neighborhood playgrounds, fast food restaurants, and crime: relationships to overweight in low-income preschool children. 3 . Preventive Medicine , 38 (1), 57-63.

[7]. Camelia, M. (2012). Impact of Integrated Marketing Communication on Consumer Behaviour: Effects on Consumer Decision - Making Process. International Journal of Marketing Studies , 4(2)

[8]. Cave, J. (2016). Digital Marketing Vs Traditional Marketing ;Which one is better ? Retrieved from www.digitaldoughnut.com assessed on 5/5/2017

[9]. Clow, K. (2010). Integrated Advertising, Promotion and Marketing Communications (4th ed.). Pearson Education, Upper Saddle River, (Chapter 1, 3).

[10]. Collis, J., \& Hussey, R. (2014). Business research: A practical guide for undergraduate and postgraduate students. Palgrave Macmillan.

[11]. Corr, F. (2007). Hotel and Catering Review. The 25th Annual Directory and Buyers Guide. . Dublin: Gemma Publications.

[12]. Damjana, J., \& Bruno, Z. (2012). Model Of Marketing Communications Effectiveness In The Business-To-Business Markets. Economic Research - Ekonomska Istrazivanja , 25(1) .

[13]. Dowler, E. (2001). Inequalities in diet and physical activity in Europe . Europe. Public Health Nutrition, 4 (2): 701- 709.

[14]. ESA. ( 2018). Earth Watching. Retrieved 08 06, 2018, from earth.esa.int/web/earth-watching

[15]. Field, A. (2009). Discovering statistics using SPSS: and sex and drugs and rock ' $n$ ' roll (3rd edition). London: Sage.

[16]. Fill, C., \& Jamieson, B. (2006). Marketing communications. Edinburgh Business School, (pp. 3 - 17).

[17]. Gosh, B. (1982). Scientific Methods and social research. New Delhi: Sterling.

[18].Jin, N., Lee, S., \& Huffman, L. (2012). Impact of restaurant experience on brand image and customer loyalty: Moderating role of dining motivation. Journal of Travel \& Tourism Marketing, 29(6), 532-551.

[19]. Kangogo, E. J., Musiega., \& Manyasi, J. (2013). Effect of Customer Satisfaction on Performance of the Hotel Industry in the Western Tourism Circuit of Kenya. European Journal of Business and Management, 5 (14).
[20]. Kaniu, S. (2007). Factors Affecting The Growth Of Foreign Food Restaurants In Nairobi, Kenya. Unpublished Thesis University Of Nairobi

[21]. Law, T. (2013). Performance Improvement Cycle. . Retrieved 07 17, 2018, from Retrieved from www.lawteacher.net

[22]. Louise, J. (2012). What is Organisational Performance? Retrieved from www.growth.pitcher.com.au

[23]. Mornay, R. ( 2009). Customer Retention Strategies of FastFood Outlets in South Africa: A Focus on Kentucky Fried Chicken (KFC), Nando's, and Steers. Journal of African Business, 10:235-249.

[24].Morrison, A., \& Teixeira, R. (2004). Small business performance: A tourism sector focus. Journal of Small Business and Enterprise Development , 11(2) 166-173.

[25]. Osborne, J., \& Waters, E. (2002). Four assumptions of multiple regression that researchers should always test. Practical Assessment, Research \& Evaluation. 8(2).

[26].Salkind, N. J. (2010). Encyclopedea research design. Retrieved from http://methods.sagepub.com /reference /encyc-of-research-design/n108.xml assessed on $12 / 2 / 2018$

[27].Short, J. C., \& Palmer, T. B. (2003). Organizational performance referents: An empirical examination of their content and influences. Organizational Behavior and Human Decision Processes, 90, 209-224.

[28].Suttle, R. (2017). Key Performance Indicators of Restaurants. Retrieved from https://bizfluent.com/info7735773-key-performance-indicators-restaurants.html retrieved on 16th April 2018

[29]. Tabachnick, B. G., \& Fidell, L. S. (2001). Using Multivariate Statistics (4th ed.). Needham Heights, MA: Allyn and Bacon.

[30].Tripathy, P., \& Tripathy, P. K. (2015). Fundamentals of Research. A Dissective View. diplom. de.

[31]. Uzel, J. M. (2012). The Effect of Strategic Value-Based Management on the Performance of Organizations in Coast Province, Kenya. International Journal of Business and Social Science , 3 ( 16).

[32]. Williams, R. (2015). Multicollinearity. Retrieved 0726 , 2018, from www3.nd.edu/ rwilliam/

[33]. Wright, B. ( 2016). The numbers game: How to measure the performance of your restaurant or cafe. Retrieved from www.mbco.com.au retrieved on 16th April 2018

[34]. Yousaf, M. (2018). Explanatory Research Definition, Types, Comparison, Advantages, disadvantages. Retrieved from scholarshipfellow.com

[35].Zhao, W., \& Jing, W. (2009). Issues, challenges and trends facing hospitality Industry:. Management science \& Engineering. , ISSN 1913-0341.

[36].Zulkiffli, S., \& Perera, N. (2011). objective A literature analysis on business performance for SMES - subjective or measures?. Conference on Interdisciplinary Business and Economic Research (pp. 1-9). Bangkok, Thailand: Society of Interdisciplinary Business Research (SIBR) 